\title{
Q uem governa por dispositivos? A produção das normas e padrões para os alimentos orgânicos no Brasil
}

Paulo Andre Niederle*

Guilherme Francisco Waterloo Radomsky ${ }^{* *}$

Resumo

O artigo analisa a construção dos sistemas de avaliação de conformidade orgânica de produtos alimentares no Brasil à luz do debate sociológico sobre dispositivos e governamentalidade. 0 foco recai sobre os conflitos que cercam a produção e o controle dos dispositivos que conformam o sistema de garantia da qualidade orgânica dos alimentos, com atenção especial aos mecanismos de certificação. A pesquisa envolveu análise documental e entrevistas com os atores sociais implicados nas instâncias de regulamentação desse mercado. Os resultados apontam para um movimento de apropriação das normas, padrões e selos pelos atores dominantes do setor agroalimentar, mas também para os contramovimentos que emergem a partir de experiências inovadoras de certificação participativa. Nesse sentido, o exemplo da Rede Ecovida de Agroecologia revela a habilidade social de atores desafiantes para construir novos dispositivos técnicos e institucionais, alterando as configurações de poder nas arenas de governo.

Palavras-chave: Mercados, Agroecologia, Instituições, Poder.

* Doutor em Ciências Sociais. Professor dos Programas de Pós-graduação em Sociologia (PPGS) e Desenvolvimento Rural (PGDR) da Universidade Federal do Rio Grande do Sul (UFRGS). E-mail: pauloniederle@gmail.com

** Doutor em Antropologia Social. Professor dos Programas de Pós-graduação em Sociologia (PPGS) e Desenvolvimento Rural (PGDR) da Universidade Federal do Rio Grande do Sul (UFRGS). E-mail: guilherme.radomsky@ufrgs.br 


\section{W ho rules by apparatuses? T he production of norms and standards for organic food in Brazil}

Abstract

This paper analyzes the construction of the systems of evaluation used in Brazil for organic foods, inspired by the sociological debate on apparatuses and governmentality. It focuseson the disputes concerning the production and control of the apparatuses that shape the system of quality guarantee for organic foods, with especial attention to the certification mechanisms. The research has combined documental analysis and interviews with the social actors concerned with the regulation instances for this market. The results expose an appropriation movement of the rules, standards and labels by the dominant actors in the agri-food sector. However, it also shows a counter-movement emerging from innovative experiences of participatory certification. In this sense, the example of the Ecovida Agroecology Network reveals the social skills of the challenging actors to build new technical and institutional apparatuses, shifting the power configurations in government arenas.

Keywords: Markets, Agroecology, Institutions, Power.

\section{Introdução}

Nas duas últimas décadas, as reconfigurações nas formas de articulação entre as três esferas de poder - Estado, mercado e sociedade civil - incitaram diversos autores a analisar a emergência de novos modelos de governo (Fligstein, 2001; Block; Evans, 2005; Ostrom, 2009). Dentre os resultados mais relevantes dessa nova geração de pesquisa social está a redescoberta dos dispositivos de regulação da atividade econômica, aplicando-se 
a uma ampla variedade de setores de atividade (Ponte; Vestergaard; Gibbon, 2011; Lascoumes; Le Galès, 2004, Fouilleux, 2012). A partir daí, a ideia de "governo por normas, padrões e dispositivos" tornou-se de uso corrente na literatura, sobretudo na sociologia econômica (Thévenot, 2015; Alphandéry et al., 2012; Busch, 2011).

A noção de "governo por dispositivos" coloca em evidência o modo como mecanismos institucionais (normas, regras, convenções, padrões, índices), intimamente associados a artefatos técnicos (leis, certificados, instruções normativas, selos, sistemas de informação), conformam o mundo, organizando as fronteiras e os formatos dos campos, fóruns, arenas ou redes dentro das quais os atores interagem e coordenam suas ações. Mais especificamente, como argumentam algumas vertentes pragmatistas da teoria sociológica, essa noção chama a atenção para o fato de que os espaços sociais são "equipados" com dispositivos que performam e ordenam as relações sociais e econômicas, classificam e estabilizam o mundo; criam trajetórias de inovação e desenvolvimento; constrangem e, ao mesmo tempo, potencializam a ação social (Thévenot, 1986; Callon, 1986).

Na sociologia dos mercados, as análises produzidas sobre essa nova forma de governo privilegiam o efeito performativo dos dispositivos (não-humanos) sobre a ação econômica (Callon, 1998). Apesar do diálogo permanente com essa questão ao longo do texto, a problemática deste artigo prioriza um aspecto menos recorrente nessa disciplina, mas amplamente debatido na sociologia política, qual seja: a produção e o controle dos dispositivos (e, por meio deles, dos mercados). A partir de um diálogo entre a sociologia política e moral de Laurent Thévenot e Luc Boltanski, a analítica do poder de Michael Foucault, e a sociologia dos mercados de Neil Fligstein, este artigo discute como os humanos manejam intencionalmente os dispositivos para controlar os mercados. 0 foco recai sobre as "habilidades 
sociais" dos atores para reformatar as condições de competição, o que implica alterar as posições relativas no "campo" (Fligstein, 2001). Ou seja, acentua o componente eminentemente político dos processos de governança dos mercados, mas sem negligenciar o fato de que, uma vez institucionalizados, os dispositivos condicionam a ação dos atores.

Essa questão é próxima daquelas colocadas por Thévenot (1997, p. 205): "Que política porta o amplo movimento de normalização dentro do qual estamos presos? Podemos falar de "política" a esse respeito, e não mais de técnica ou de economia, dirigindo as normas que governam as coisas?" Ao mesmo tempo, nos remete à discussão foucaultiana sobre "governamentalidade", ou seja, para o modo como os dispositivos são utilizados e orientados a conformar distintos regimes de conhecimento e poder (Foucault, 2008a). Sob esse ponto de vista, aborda-se a tensão entre as formas de governo da vida e a ação dos indivíduos. No centro da análise está o conflito entre, por um lado, os atores que detêm maior "poder de disposição" (de controle dos dispositivos) e, por outro, aqueles que criticam a ordem estabelecida e tentam construir novos dispositivos com vistas a alterar suas posições relativas nos mercados. Ou seja, entre atores "incumbentes" e "desafiantes" (Fligstein, 2001).

Essa problemática emergiu a partir de uma pesquisa sobre a construção dos sistemas de avaliação da conformidade orgânica para produtos alimentares no Brasil. No setor agroalimentar, o mercado para alimentos orgânicos tem se consolidado como um dos mais promissores no país. Em parte, isso se deve à estabilização de um conjunto de dispositivos de governo, dentro os quais se destacam as normas de produção, os padrões de qualidades e, sobretudo, o selo que qualifica e identifica os produtos orgânicos. Após um intrincado processo de disputa e concertação social entre atores de diferentes segmentos (agricultores, técnicos, pesquisadores, empresas de processamento, certificadoras, supermercados etc.), a estabilização desses dispositivos 
permitiu a criação de um sistema em que operam três mecanismos de garantia da qualidade: auditoria externa, certificação participativa e organização de controle social para venda direta. 0 artigo analisa como esse sistema foi produzido, bem como o posicionamento dos atores e as disputas decorrentes da coexistência dos mecanismos, os quais se associam a distintas formas de poder e conhecimento.

Os resultados apresentados são oriundos da pesquisa "Normatizar em nome de qual Desenvolvimento? A construção dos mecanismos de regulação nos novos mercados alimentares", financiada pelo CNPq, e levada à cabo entre 2015 e 2017. Nessa investigação, realizou-se análise documental e entrevistas com interlocutores chave no que diz respeito à produção das normas e padrões para alimentos orgânicos no Brasil, sobretudo, com gestores, pesquisadores e lideranças sociais que participam das instâncias sociais de regulação deste mercado - com destaque para a Comissão Nacional de Agroecologia e Produção Orgânica (CNAPO), órgão de composição paritária entre governo e sociedade civil, sob responsabilidade de Secretaria Geral da Presidência da República.

O artigo está organizado em seis seções, além desta introdução. A primeira apresenta uma revisão sobre as principais perspectivas das ciências sociais que tratam do papel dos dispositivos na estruturação dos mercados e da ação pública. A segunda focaliza a relação entre governo, normatização e certificação nos mercados alimentares, ao que segue a quarta seção centrada especificamente no mercado de alimentos orgânicos. A quinta introduz resultados de pesquisa, destacando o movimento de apropriação da certificação orgânica pelos atores dominantes do setor agroalimentar, o que tem sido tratado pela literatura como "convencionalização dos orgânicos" (Guthman, 2004). Em seguida, a sexta seção discute os contramovimentos que emergem a esse processo, em particular a experiência da Rede Ecovida de Agroecologia, a qual revela um esforço de construção de 
novos dispositivos e novos mercados, e que tem implicações nas configurações de poder e nas lógicas de governo. Finalmente, as conclusões sugerem que as lutas pelo controle dos dispositivos têm se complexificado em virtude da proliferação e sobreposição dos mercados. Nesse sentido, chama atenção o fato de que os mesmos dispositivos começam a ser mobilizados por diferentes atores e em distintos mercados, o que não apenas questiona as fronteiras entre os "campos", como dificulta a identificação e classificação de dominantes e dominados.

\section{Governar por D ispositivos: diferentes quadros de análise}

0 conceito de "dispositivo" foi incorporado à caixa de ferramentas analíticas de diferentes abordagens das ciências sociais. Nesta seção sintetizamos as principais diferenças entre aquelas mais recorrentes nos debates sobre mercados.

\subsection{D ispositivos como soluções ef icientes para as falhas de mercado}

$\mathrm{Na}$ fronteira entre as ciências econômicas e da gestão, a ideia de dispositivo é primeiramente abarcada pela sua função de "racionalização" da ação econômica. Nessa perspectiva, o termo define um conjunto de instrumentos que estruturam as organizações e os mercados, garantindo a eficiência dos processos de produção e comercialização. Dentre as principais características desse tipo de abordagem está, em primeiro lugar, a própria crença na capacidade humana de racionalização do mundo, bem como da ciência como o único meio eficaz para cumprir tal objetivo. Nessa perspectiva, os dispositivos "comunicam certezas", garantindo o domínio e a vigilância do corpo social. Soma-se a isso a compreensão de que existe um, e apenas um, melhor modo de organizar os processos produtivos. A partir daí, as mesmas técnicas de management passam a ser difundidas globalmente (Feigenbaum, 1994). 
Essa perspectiva passou por inúmeros aprimoramentos ao longo do tempo. A Teoria dos Custos de Transação e, mais amplamente, a Nova Economia Institucional ampliaram a análise sobre o papel dos dispositivos na redução das incertezas, as quais foram transformadas em riscos calculáveis, e no controle da "propensão ao oportunismo" dos agentes econômicos. Esse ponto de vista reconhece que a racionalidade dos atores é limitada, sobretudo devido à assimetria informacional que prevalece nos mercados, e que fazem dos custos de transação um fator que bloqueia a dinâmica econômica e o desenvolvimento. Em decorrência disso, contratos e sistemas de certificação emergem como dispositivos privilegiados para corrigir as chamadas "falhas de mercado" (Williamson, 2012).

\section{$1.2 \mathrm{D}$ ispositivos como ef eitos de disputas normativas}

Outras vertentes do institucionalismo abarcam de maneira mais complexa o modo como regras, valores, padrões e normas são criados e conformam o arranjo normativo que orienta o comportamento dos atores e organizações (Fligstein, 2001). Ao invés de uma solução ex-ante para o 'inadequado funcionamento do mercado' ( $\mathrm{sic}$ ), essas vertentes sublinham as lutas políticas entre diferentes atores em torno da construção, legitimação e estabilização de dispositivos de governança (Biggart; Beamish, 2003). Nessa perspectiva, não existe 'melhor escolha', mas disputas entre dispositivos que competem para se legitimar e para impor suas formas de ordenamento do mundo. A escolha envolve dependência de caminho (path dependence), aprisionamento institucional (lock-in) e eficiência institucional, ou seja, a capacidade do dispositivo em se adequar ao sistema de regras historicamente constituído - mesmo que isto implique menor eficiência econômica ou tecnológica (deste modo, não prepondera um critério de racionalização) (Hodgson, 2006).

Dentre as inúmeras vertentes institucionalistas, a socioeconomia das convenções prioriza a questão do uso dos dispositivos 
nos processos de qualificação e categorização do mundo social (Boltanski; Thévenot, 1991). Em geral, os autores dessa escola colocam menos ênfase na "dependência de caminho" institucional, conferindo maior margem de manobra para os atores alterarem as trajetórias. Nessa perspectiva, destacam as "lutas por justificação" nas quais os atores sociais se engajam para legitimar a escolha e o uso dos dispositivos. As dificuldades dessa escolha não decorrem da falta ou assimetria de informações, mas dos diferentes quadros de interpretação (Thévenot, 1986; Eymard-Duvernay, 1989). Ou seja, a questão é reposicionada dentro de um contexto de "incerteza radical". O problema não é acessar as informações necessárias para otimizar um cálculo de utilidades preconcebido teoricamente, mas como eleger, frente a uma pluralidade de mecanismos de escolha, o melhor procedimento de "cálculo" (ou, nos termos utilizados por esses autores, o melhor "princípio de julgamento"). Nesse sentido, a escolha dos dispositivos assume um caráter eminentemente político e moral (isto é, valorativo).

\subsection{D ispositivos como signos linguísticos e artef atos sociotécnicos}

Dialogando de maneira muito próxima à perspectiva convencionalista, mas acentuando os aspectos mais propriamente cognitivos ao invés dos conflitos valorativos, as teorias da linguagem definem os dispositivos como signos comunicacionais. Estes signos estruturam "narrativas" que conferem sentido à vida social, pelo menos para aquela "comunidade" de sujeitos que compartilham o mesmo mundo, e que precisam construir sentidos que tornem a realidade inteligível (Blandin, 2002). Ou seja, nessa perspectiva, dispositivos estruturam e estabilizam narrativas, as quais passam a agir como receitas para a realidade (Schmidt, 2008). A definição também implica a manipulação de objetos, normas, regras, padrões e leis, mas, antes de tudo, remete à construção de símbolos, sentidos e representações, o que ocor- 
re nos espaços de interação social. Por fim, comparativamente às vertentes institucionalistas, o elemento histórico está menos presente aqui.

De outro modo, apesar de adotar uma perspectiva igualmente interacionista, a "teoria do ator-rede" adiciona um forte componente pragmatista, o que a leva a ressaltar os dispositivos como artefatos indispensáveis aos processos de agenciamento e ordenamento do mundo. Nas redes sociotécnicas importa uma simetria em que não há distinção entre os "actantes" (humanos e objetos), como também não há atores isolados ou amplas estruturas sociais dominadoras (Callon, 2008). 0 mundo se constitui em uma estrutura reticular e plana, em que o que deve ser analisado são os processos de "tradução", responsáveis por tornar mundos estranhos inteligíveis (Latour, 2008). Os dispositivos jogam um papel central nesses processos, não apenas intermediando as formas de tradução, mas permitindo "ação à distância". Através deles os "macroatores" ${ }^{1}$ coordenam as ações dos demais, organizando o fluxo de informações, recursos e mercadorias. Neste caso, também se nota um estreito diálogo com a teoria das convenções, para quem a "agência está situada em um ambiente material”. (Thévenot, 2015, p. 199).

\subsection{D ispositivos como mecanismos de dominação e governamentalidade}

No amplo e controverso campo de pesquisa social definido como "teoria crítica", predomina a compreensão dos dispositivos como mecanismos materiais e simbólicos de dominação, utilizados por uma classe, categoria ou grupo com vistas a assegurar

1 Callon (2008) identifica grande centralidade dos técnicos e pesquisadores nas sociedades modernas ocidentais, os quais exercem uma atividade "performativa" sobre o mundo, sem que isto implique no mesmo tipo de olhar racionalista presente nas teorias organizacionais. Trata-se, antes de tudo, de analisar politicamente a formação de uma tecnociência. 
posições sociais, hierarquias e classificações socialmente legitimadas. Aqui se encontram perspectivas analíticas e orientações epistemológicas reconhecidamente distintas, que compartilham a atenção aos conceitos de poder e dominação. Nesse caso, o foco da análise volta-se para: (1) os processos de reificação do mundo social - o papel dos dispositivos em ampliar a fixidez, o automatismo e a passividade dos atores (Honneth, 2005); (2) para a violência simbólica que se associa ao seu uso como marcadores de status e distinção social (Bourdieu, 2007); e (3) para o modo como os atores dominantes manejam regras e recursos em favor de suas estratégias econômicas, as quais também são eminentemente políticas (Fligstein; McAdam, 2011).

Não obstante, enquanto alguns autores privilegiam um olhar macroestrutural para esses processos, outros procuram desvendar a microfísica que subjaz os usos mais cotidianos dos dispositivos como meios de governamentalidade (Foucault, 2008a). Nessa perspectiva, a dominação não é externa (recaindo sobre os indivíduos como uma sanção), mas refere-se ao modo como os sujeitos incorporam normas, rotinas e hábitos que "disciplinam" ou "controlam" seus comportamentos, moldando não apenas as relações sociais, mas os corpos e a natureza. Ao mesmo tempo, esses autores conferem mais ênfase às possibilidades de reação, demonstrando que a resistência antecede o poder. Essa compreensão está muito presente em Foucault (1999), que também associa estas disputas às diferentes formas de conhecimento, poder e controle que os dispositivos incorporam.

\subsection{U ma proposta de diálogo entre a analítica do poder e a sociologia pragmática}

Como se pode apreender até aqui, existe um rico campo de estudos sobre a noção de "governança por dispositivos". Apesar das significativas diferenças teóricas, as abordagens acima sumarizadas desnaturalizam as normas, regras, padrões, índices, selos 
etc., apontando para distintas formas de analisar sua "construção social”. À primeira vista pode parecer que essas abordagens são irreconciliáveis. No entanto, um olhar mais cuidadoso para a literatura recente revela inúmeros esforços de aproximação (Blandin, 2002; Busch, 2013; Ponte; Gibbon, 2005). Nas próximas seções, analisando a construção do mercado de alimentos orgânicos no Brasil e, em particular, a institucionalização dos mecanismos de certificação, exploramos algumas possibilidades de diálogo. 0 foco volta-se às interfaces entre a sociologia política e moral de Laurent Thévenot e Luc Boltanski e a analítica do poder de Michael Foucault. Complementarmente, com o objetivo de aproximar o debate da sociologia dos mercados, o artigo também traça algumas pontes com os conceitos de Neil Fligstein.

Apesar de não ser muito recorrente no debate sociológico, até porque impõe pensar nas conexões epistemologicamente pertinentes entre o pós-estruturalismo (Foucault) e a teoria pragmática (Boltanski/Thévenot), este diálogo é estimulado pelo reconhecimento dos próprios autores de referência acerca dos pontos de contato entre suas teorias, como é precisamente o caso da discussão sobre dispositivos e poder. Conforme alude Thévenot (2015), as convenções sociais adentram ao mundo dos atores por meio de uma série de dispositivos materiais, ocasionando mudanças no modo como o poder é socialmente distribuído. Com efeito, complementa o autor, "esta visão é bastante compatível com a compreensão de Foucault sobre micro-poder [...] nas relações e técnicas que são colonizadas, usadas, moduladas, transformadas, deslocadas, estendidas e assim por diante, por meio de um aumento generalizado dos mecanismos e formas de dominação".

Foucault (1999) observou as mudanças nos mecanismos de poder na sociedade moderna ocidental. Segundo o autor, o disciplinamento apoiado na vigilância dos corpos (entre os séc. XVII e XVIII) foi gradualmente substituído por uma manifestação 
do poder sobre o homem-espécie enquanto ser vivo (entre os séc. XVIII e XIX), apostando no cuidado da população através de controles "pela" liberdade e em "fazer viver" a população. Os novos estudos em biopolítica demonstram a continuidade histórica desses processos. Para Blaser (2010), as novas tecnologias de controle que correspondem à lógica do enquadramento (framing) são chamadas de "técnicas pós-disciplinares". Elas sugerem a vontade "livre autônoma" das pessoas, o que faz a intervenção aparecer como não-intervenção - ou, como afirmou Foucault (2008b) sobre o (neo)liberalismo, o "governo como não-governo".

Essa perspectiva se aproxima das mais recentes formulações de Boltanski (2013) sobre as novas formas de "dominação gestionária" no capitalismo contemporâneo. Apoiando-se em dispositivos com pretensa neutralidade (invocadas a partir da legitimidade da ciência e da técnica), esse sistema articula mecanismos de controle que escondem a realidade do processo social e político de construção das normas, regras, leis, índices e modos de cálculo. Assim sendo, ainda que materializados pela ação dos indivíduos, esses dispositivos continuam a ser mais ou menos impessoais, de modo que "a questão de saber quem são os dominantes muitas vezes tem um caráter problemático" (Boltanski, 2013, p. 449, itálico no original). Mesmo assim, há notórias diferenças de poder: enquanto dos dominados espera-se que eles considerem os dispositivos como "se fossem quase sagrados e ajam seguindo as regras ao pé da letra", os dominantes "podem adotar uma relação prática, e de alguma forma dessacralizada, com as instituições simplesmente porque eles as fazem" (ibidem, p. 452, itálico no original).

\section{$2 \mathrm{M}$ ercados alimentares governados por normas e padrões}

Inúmeros autores consideram que os mercados agroalimentares estão entre os mais afetados pela emergência dos novos 
modelos de governo por dispositivos (Alphandéry et al., 2012, Bingen; Busch, 2007). As principais evidências disso se consolidaram nos anos 1990, quando proliferaram estudos sobre a transformação no modo de ação do Estado em relação à agricultura, os quais demonstraram como o mesmo abdicou de sua postura eminentemente intervencionista para assumir uma posição prioritariamente reguladora da ação privada (Allaire; Boyer, 1995; Nicolas; Valceschini, 1995).

As primeiras experiências desse novo tipo de intervenção estiveram associadas à aplicação dos sistemas de certificação de práticas e processos agroindustriais, com foco prioritário no controle dos aspectos voltados para uniformização e sanidade (ISO, APPCC, BPF) ${ }^{2}$. Não obstante, com a consolidação da narrativa neoliberal, os dispositivos se diversificaram. Juntamente com novas normas e padrões, foi produzida uma miríade de selos, certificações, atestados, registros, indicadores e testes (Fouilleux, 2012; Guéneau, 2009). Além disso, como destacam Shore e Wright (2015), pode-se notar um incrível "salto de escala". Se até o final dos anos 1980 a maioria desses dispositivos estava limitada a alguns Estados nacionais, a partir deste momento assistiu-se a sua disseminação global.

De fato, os anos 1990 são marcados por um processo de institucionalização dessas novas formas de governo em esferas supraestatais. Destaca-se, nesse sentido, o papel de empresas transnacionais do setor alimentar, sobretudo conglomerados varejistas, as quais assumiram uma posição privilegiada (incumbentes) na estruturação deste campo social. Um dos exemplos mais conhecidos desse fenômeno é o Global Good Agricultural Practices (GLOBALG.A.P.), o qual define um conjunto de padrões voluntários para certificação de produtos agrícolas amplamente adotado pelas maiores corporações globais como Wallmart, Tesco,

2 Respectivamente: International Organization for Standardization, Análise de Perigo e Pontos Críticos de Controle, Boas práticas de Fabricação. 
Lidl, McDonalds, entre outras. Outro exemplo, mais voltado para o setor de processamento agroindustrial, envolve a proliferação das multi-stakeholderroundtables, as quais têm produzido acordos entre o setor corporativo acerca de questões relacionadas, por exemplo, com a certificação da sustentabilidade ambiental e das condições de trabalho. Em ambos os casos, como destaca Thévenot (2015), nota-se como os novos formatos de governo, que combinam a gramática liberal e o modo de governar por standards, criam fortes constrangimentos institucionais para determinados atores, sobretudo para os pequenos agricultores.

O modo como essas pressões institucionais operam sobre os atores tem sido objeto crescente de interesse. De modo geral, nos estudos sobre cadeias globais de valor prepondera uma análise macroestrutural, a qual reconhece os efeitos que a nova gramática normativa produz na reconfiguração das relações entre Estado e Mercado, mas tem dificuldades para adentrar na microfísica destes processos. De acordo com Shore e Wright (2015), a institucionalização em nível mundial desses dispositivos é acompanhada por um fenômeno de interiorização que a naturaliza e a torna parte de nossas vidas, conectando, assim, as dimensões globais ao comportamento cotidiano. Nos termos de Mary Douglas (1998), o processo de incorporação dos dispositivos ao mundo da vida revela uma verdadeira "naturalização" das classificações e princípios de julgamento social, de modo que o grande triunfo do "pensamento institucional" é tornar os dispositivos completamente invisíveis.

Uma vez construídos, os dispositivos se desprendem dos atores e passam a operar como se fossem um "constructo natural", afirmando uma realidade inquestionável. Na medida em que invocam "forças impessoais e inexoráveis", subordinam a vontade dos atores "às leis inscritas na natureza das coisas" (Boltanski, 2013, p. 453). 0 modo de "governar por números e rankings" (Miller, 2001) esconde seus agentes disseminadores, distribuindo-se em uma complexa malha de relações sociais. "A este respeito, 
governantes e governados, dominantes e dominados enfrentam o mesmo problema. Eles são, todos, supostos servidores da realidade. A todos eles se pede para serem realistas" (Boltanski, 2013, p. 451). Evita-se, assim, o perigo da crítica, pelo menos da crítica política, já que tudo assume a imagem aparentemente inquestionável da neutralidade (técnica) dos dispositivos. Ou seja, qualquer crítica somente é aceita nos termos da própria realidade que os dispositivos constroem.

Nesses termos, um dos maiores desafios da pesquisa social passa a ser a reconstrução dessa teia de relações sociais, o que permitiria ver os "atores de peso" em ação. Para além do setor corporativo, Shore e Wright (2015) demonstram, por exemplo, como as big 4 companies de auditoria - Deloitte, PricewaterhouseCoopers, Ernst and Young e KPMG - cresceram às custas das mudanças nas formas de governança, favorecidas pelas novas regras e requerimentos para todas as empresas, as quais passaram a ser "verificadas" pelas firmas de auditoria. "Como elas ajudaram governos a expandir a noção de auditoria, seu portfólio de atividades - e fluxo de caixa - aumentou" (Shore; Wright, 2015, p. 25). Aumentou a tal ponto que reconfigurou o próprio mercado para serviços de auditoria (Johnson; Lys, 1990).

A "governamentalidade neoliberal" (Foucault, 2008b) criou dispositivos inovadores de regulação e controle, os quais demandam uma política ativa e vigilante, mas sem o protagonismo direto do Estado. Esse tipo de ação levou a uma agenda de desregulação por meio da produção de soft laws, cujo grau de enforcement institucional seria relativamente pequeno, considerando que se tratam, geralmente, de padrões voluntários. Mas, considerando sua ampla disseminação, esses dispositivos tornam-se mecanismos poderosos de controle e dominação - constituindo uma "cultura de auditorias" (Strathern, 2000) que remete justamente às formas pós-disciplinares de governo. Tanto é assim que, de modo geral, "os promotores deste novo modo de gover- 
no com soft laws argumentam que ele é mais reativo e próximo à prática do que as leis" (Thévenot, 2015)³.

É verdade que a reconfiguração dos mercados alimentares é mais complexa e contraditória. Existem reações a esses processos por parte de atores desafiantes. "Enquanto eles reconhecem a natureza do campo e a lógica dominante dos atores incumbentes, eles geralmente podem articular uma visão alternativa do campo e das suas posições nele..." (Fligstein; McAdam, 2011, p. 6). Esses atores buscam criar condições para alterar as regras que organizam o mercado (campo), ou criar espaços específicos (nichos/subcampos) dentro dos quais podem adquirir certa autonomia para manejar normas e dispositivos. A possibilidade disso acontecer depende de uma série de fatores. Por um lado, da capacidade desses atores para desencadear um movimento de crítica e contestação social, questionando os valores que sustentam os dispositivos dominantes e oportunizando - ou legitimando - a criação de novos. Obviamente, os atores dominantes farão de tudo para bloquear a possibilidade da crítica, desqualificando, tornando-a ilegítima, afirmando que seus preceitos são "irrealistas". E, quando não conseguirem bloqueá-la, tentarão ao menos se apropriar da mesma, tornando-a um instrumento "reformista", incapaz de alterar profundamente as classificações e hierarquias já estabelecidas (Boltanski, 2009).

Por outro lado, depende dos resultados alcançados pelos "investimentos" (Thévenot, 1986) que os atores desafiantes fazem para produzir o engajamento ao seu projeto, o que implica no uso de capitais físicos, institucionais e cognitivos (Fligstein,

3 Corroborando um dos principais argumentos dos autores neoinstitucionalistas e convencionalistas, muitas vezes esse tipo de acordo privado tem efeitos sobre os comportamentos sociais mais evidentes do que o aparato normativo formal produzido pelos governos (Batifoulier; Larquier, 2001). Em alguns casos, eles são inclusive capazes de se projetar para dentro dos dispositivos públicos - haja vista, por exemplo, como as normas e padrões do GLOBALG.A.P foram incorporados no Regulamento de Uso da Indicação de Procedência registrada pelos produtores de Uva e Manga do Vale do São Francisco, no Brasil. 
1997). Nesse sentido, como discutiremos na penúltima seção em relação à Rede Ecovida, destaca-se o papel que organizações não governamentais (ONGs) e movimentos sociais passaram a desempenhar na construção de novas infraestruturas institucionais e técnicas, mas também no manejo de identidades sociais (agroecologia vs. orgânicos), para a construção de novos mercados (Radomsky; Niederle; Schneider, 2015). A habilidade desses atores também é importante para ampliar a cooperação com as organizações do Estado, ou, mais precisamente, em criar as condições para que uma nova coalizão seja produzida, a qual, se não é capaz de alterar radicalmente a lógica institucional do campo, ao menos pode assegurar um espaço específico de ação, como é precisamente o caso que ocorreu com a agricultura familiar nas últimas duas décadas, em face de um campo social amplamente dominado pelos atores do agronegócio.

\section{0 uso dos selos de certificação}

No que tange ao tema específico das certificações nos mercados alimentares, os estudos acerca dos mais diversos tipos de selos que emergiram nas últimas décadas têm apresentado distintas perspectivas sobre este fenômeno. De um lado, há resultados de investigação mais otimistas com relação aos efeitos positivos que as certificações produzem para as economias locais na medida em que potencializam a construção de mercados diferenciados. De outro, estudos menos entusiastas demonstram as relações de poder implicadas e as formas de distinção que se atualizam com esses instrumentos (Goodman; Goodman, 2007). Sem esgotar a diversidade de interpretações, ambas as vertentes parecem concordar com relação à relevância do fenômeno, haja vista a "inflação de selos" nas cadeias agroalimentares (Hatanaka et al., 2005; Mansfield, 2004).

Bostrom e Klintman (2008) sugerem que os selos são ferramentas de síntese, uma vez que aglutinam ideias e valores em um único 
emblema. De fato, os selos simplificam a mensagem, sintetizando características em uma imagem unificada. No entanto, essa questão se torna muito mais complexa quando se analisa o panorama geral das certificações, em que os selos competem entre si ou se sobrepõem em funções (diferentes selos para o mesmo tipo de "qualidade"). Esse é o problema da "inflação dos selos". Mesmo que haja estudos mostrando o quanto as certificações atuam para proporcionar transparência na relação produtor-consumidor (argumento baseado na assimetria da informação que sempre favorece o produtor), cresce a insatisfação com o excesso de selos e com a cultura de auditorias. Esse problema incide, principalmente, em situações (muito comuns) nas quais os atores podem lançar mão de mais de um selo para um único produto ${ }^{4}$.

Howard e Allen (2006) citam três principais funções dos selos de certificação na agricultura. Primeiro, eles informam aos consumidores a respeito de características do produto que não são visíveis, aparentes ou capazes de ser verificadas no ato da compra (tipo de mão-de-obra, utilização de agrotóxicos, sistema de extração etc.). Segundo, podem servir como mecanismos para implementação de políticas públicas, na medida em que orientam a ação social em torno de uma determinada agenda. Terceiro, podem favorecer nichos de mercado, facilitando, por exemplo, o crescimento das vendas para produtores que seguem os processos ecológicos de cultivo. Mas essas três funções oferecem apenas um ponto de partida para o entendimento do fenômeno, pois as relações que derivam dos processos de certificação são mais complexas.

Ilbery et al. (2005) sustentam que as certificações geralmente se fundamentam em três pilares: o produto, o processo e o lugar.

4 Em virtude disso, há autores apontando para uma "segunda geração de selos" (Ramos; Garrido, 2014). Enquanto a primeira teria sido marcada por um "labirinto de selos", a segunda apostaria em "selos e marcas territoriais" que, "para simplificar a mensagem e reduzir a hipertrofia do sistema de diferenciação da qualidade" (Ramos; Garrido, 2014), buscam combinar atributos sociais, ambientais e culturais, apostando no território como elemento unificador (Wilkinson; Niederle; Mascarenhas, 2016). 
Para os autores, a maior parte das iniciativas utiliza dois desses aspectos combinados. A certificação funciona como um diferenciador; ela atesta a origem e incide no produto (se é raro, de qualidade, etc.) associando-o à maneira como é produzido (o processo) ou ao lugar (as condições sociais e naturais). Esses aspectos combinados têm efeitos no modo como as estratégias de mercado são acionadas pelos atores sociais. De modo geral, aposta-se nesses dispositivos como mecanismos agenciadores de processos econômicos (a capacidade performativa referida na introdução), o que faz sentido em um contexto de economias de qualidade, ou seja, de distinção de produtos, processos e lugares para mercados segmentados (Callon, Méadel e Rabeharisoa, 2002).

A literatura parece indicar, de um lado, que o uso desse tipo de dispositivo para organizar e planejar estratégias de desenvolvimento incorre em utilizar das racionalidades e das potencialidades dos selos, apostando em economias diferenciadas, porém controladas por standards (Busch, 2013). Nesse sentido, Renting et al. (2003) sugerem uma dimensão potencializadora desses dispositivos, particularmente na estruturação de circuitos ampliados, haja vista a capacidade dos selos em converter mercados de longas distâncias em cadeias curtas, isto porque o conhecimento do produto pelo consumidor e o enraizamento (embeddedness) dele nos locais em que é gerado criam sentidos compartilhados.

De outro lado, há uma compreensão crítica a respeito dos constrangimentos e iniquidades que esses dispositivos produzem e naturalizam. 0 sistema global de certificações é uma construção social e sua história mostra que países e atores privilegiados tiveram mais poder para constituir normas e formatos de controle, inclusive instituindo a "ciência" (moderna e ocidental) como princípio legitimador dos valores e interesses que os dispositivos incorporam (Appleton, 2001; Fonseca, 2005). Países como o Brasil não constituíram as normas para os alimentos orgânicos (e a respectiva política de certificações) sem que tivessem sido 
firmados acordos internacionais, e foi, inicialmente, por pressão externa que o país articulou esforços para a regulação deste mercado (Radomsky, 2015) ${ }^{5}$.

Enfim, há diferentes posicionamentos em relação às certificações agroalimentares e suas potencialidades (ou problemas) para performar trajetórias de desenvolvimento econômico, ora pendendo para possibilidades de reconexão (produtor-consumidor, rural-urbano), ora demonstrando as assimetrias de poder que se renovam a partir deste fenômeno. 0 que ambos parecem concordar é que esses dispositivos, e suas formas de padronização/ diferenciação, dizem muito sobre as formas de governo no capitalismo contemporâneo. A gama variada de estudos e pesquisas sobre o tema indica que os selos funcionam como dispositivos fundamentais na atribuição de valores, agenciando elementos materiais, mas também intangíveis e simbólicos.

\section{A institucionalização do mercado de alimentos orgânicos no Brasil}

A conformação do mercado de orgânicos no Brasil envolveu diferentes atores e espaços de governança. Esse processo remonta, pelo menos, às críticas desencadeadas nos anos 1980 aos efeitos socioambientais do processo de modernização da agricultura. Ainda que ocupando uma posição subjugada no campo social, organizações e movimentos ecologistas conseguiram repercutir suas críticas ao potencial poluidor da atividade agrícola e aos efeitos nocivos dos agrotóxicos à saúde humana. Embora isso não tenha desencadeado uma ampla revolução no campo, que

5 Há ainda acusações de uma espécie de "retórica" da proteção ambiental, particularmente para as normas de orgânicos. 0 estudo de Lyon (2006) sugere que, enquanto se apresentam publicamente justificativas para a transição em direção a uma agricultura mais sustentável em países do Sul Global, ela parte de consumidores e intelectuais mais preocupados com pureza cultural ou rotas de aves migratórias na Europa e nos Estados Unidos do que com condições sociais de trabalho em outros países. 
seguiu dominado pelos adeptos da "revolução verde"6, aqueles atores foram suficientemente hábeis para constituir um espaço específico (uma espécie de nicho social) para as formas alternativas de agricultura.

Em meados dos anos 1990, o tema adentrou à agenda das organizações do Estado. Isso se deu menos em virtude da pressão dos movimentos sociais nacionais do que pela demanda dos mercados internacionais, mediada pelos acordos multilaterais no âmbito da Organização Mundial do Comércio, em 1994 (Radomsky, 2015). Nesse sentido, foi instituído pelo Governo Federal o Comitê Nacional de Produtos Orgânicos (CNPO), reunindo representantes de ONGs, do Ministério da Agricultura (MAPA), da Empresa Brasileira de Pesquisa Agropecuária (Embrapa), do Ministério do Meio Ambiente e de Universidades, os quais foram responsáveis por conceber o embrião da atual legislação que regulamenta o mercado de orgânicos. Em 1998, o MAPA publicou a Portaria 505, propondo a normatização dos produtos orgânicos. Após consulta pública sobre o teor da mesma, foi publicada a Instrução Normativa 07/99, a qual constitui a primeira regulamentação nacional definindo a produção orgânica e estabelecendo as normas de produção, tipificação, processamento, envase, distribuição, identificação e certificação de qualidade (Niederle; Almeida, 2013).

De modo geral, essas normas responderam às exigências que alguns países começavam a criar para permitir a entrada dos produtos orgânicos nos seus respectivos mercados (sobretudo os mercados europeus). Apesar da crítica que os movimentos ecologistas dirigiram às mesmas, elas começaram a forçar os agricultores a alterar seus sistemas de produção. Ao mesmo tempo, a criação de um mercado global estimulou a proliferação dos sis-

60 termo faz referência a um movimento de mudanças abruptas da base técnica de produção agrícola que, no Brasil, foi potencializado por políticas de modernização da agricultura a partir dos anos 1960. Esse fenômeno é geralmente apontado como o principal responsável pela configuração do atual regime agroalimentar global (Allaire e Boyer, 1995). 
temas de certificação de terceira-parte, os quais passaram a atuar em estreita sintonia com corporações privadas, notadamente com as redes varejistas multinacionais, que ajudaram a estabelecer os padrões de qualidade e, com isto, impuseram inúmeras transformações aos sistemas agrícolas locais, inclusive nas agriculturas de base ecológica (Hatanaka; Bain; Busch, 2005).

A gradativa expansão do mercado interno também passou a demandar mecanismos de controle sobre o uso indiscriminado de selos e nomenclaturas que associavam uma vasta gama de produtos a diferentes sistemas ecológicos de produção, nem todos com regras claramente definidas. Além de gerar disparidades entre os produtores, essas práticas confundiam os consumidores (o problema do oportunismo e da assimetria de informações), os quais eram atraídos por distintas expressões que faziam apelo a um conjunto de preocupações sociais emergentes, particularmente aquelas associadas à saúde e preservação ambiental - e que ainda hoje são vastamente encontradas nos produtos a despeito da falta de regulamentação - tais quais: ecológico, saudável, natural, artesanal, caseiro etc.

Por mais controverso que tenha sido o "compromisso" 7 produzido em torno do termo "orgânico", ele foi decisivo à estabilização do mercado. Sua institucionalização refletiu a posição dos atores incumbentes no campo (gestores estatais, pesquisadores, técnicos, empresas e certificadoras), os quais projetavam neste signo uma determinada concepção tecnocientífica de qualidade. Os movimentos agroecológicos esforçaram-se em deslegitimá-la, alegando que a mesma se ancorava em um conjunto de conhecimentos e dispositivos estranhos à realidade da ampla maioria dos agricultores. Essa luta normativa evidenciou o conflito entre uma agricultura orgânica "tecnocrática"

7 Para Boltanski e Thévenot (1991), "compromissos” são composições específicas que emergem do encontro de diferentes ordens de grandeza valorativas ("mundos"). Trata-se de uma chave de leitura para interpretar a formação de arranjos híbridos, nos quais valores, objetos e pessoas aparentemente irreconciliáveis são dispostos de maneira relativamente ordenada, produzindo estabilidade. 
(mercantil-industrial) e uma agroecologia "sociopolítica" (doméstico-cívica). E, embora os movimentos agroecológicos não tenham conseguido fazer prevalecer sua concepção de agroecologia, eles foram hábeis para garantir que a certificação oficial "orgânica" não suplantasse o uso de outras convenções, as quais ainda hoje se mantêm nos produtos: agroecológico, biológico, biodinâmico, permacultura. Essa habilidade incluiu, dentre outras coisas, o diálogo com os novos atores que adentraram nas esferas de governo após a eleição do presidente Lula, muitos dos quais eram oriundos dos movimentos sociais (sobretudo no então Ministério do Desenvolvimento Agrário). Ou seja, esse processo envolveu a conquista de importantes espaços de produção de dispositivos de governo.

O embate entre agroecologia e produção orgânica bloqueou parcialmente novos entendimentos normativos, bem como a expansão dos mercados. Por conta disso, os atores empresariais aguardaram um arranjo institucional ainda mais favorável aos seus interesses para investir mais fortemente no setor. Somente em 2007 uma situação de maior estabilidade foi alcançada com a promulgação do Decreto 6.323/2007, que regulamenta a Lei 10.831/2003, chamada de Lei dos Orgânicos. Embora a lei tenha inserido apenas pequenas modificações na redação que define os sistemas orgânicos de produção, sem alterar substancialmente aquilo já especificado na IN 07/99, trata-se de um dispositivo institucional que confere maior estabilidade às decisões dos atores no mercado. Por sua vez, o Decreto promoveu importantes ajustes normativos ${ }^{8}$ e, principalmente, estabeleceu o Sistema Brasileiro de Avaliação da Conformidade Orgânica (SISOrg).

8 À título de exemplo, enquanto a IN 07/99 estabelecia períodos fixos de "conversão" das unidades produtivas para os sistema orgânicos (12 ou 18 meses para cultivos anuais ou perenes, respectivamente), o Decreto 6.323, em seu art. 6o, determina que "o período de conversão variará de acordo com o tipo de exploração e a utilização anterior da unidade, considerada a situação socioambiental atual" e "as atividades a serem desenvolvidas durante o período de conversão deverão estar estabelecidas em plano de manejo orgânico da unidade de produção". Essa flexibilização foi alcançada após uma longa discussão envolvendo diferenças conceituais e políticas acerca dos processos de "conversão" ou "transição" agroecológicas. 
A construção do SISOrg revela o amplo processo de negociação entre os atores desse campo social. Assim como já existia no contexto internacional, reconheceu-se o uso de auditoria externa, sistema que transfere o controle da qualidade a um organismo público ou privado de avaliação da conformidade. Esse sistema regulamentou o trabalho das empresas certificadoras que, desde então, apresentaram um crescimento significativo no mercado brasileiro. No entanto, juntamente com a auditoria externa, e basicamente por demanda dos movimentos sociais, foram criados os Sistemas Participativos de Garantia (SPG), nos quais o controle é exercido por uma entidade jurídica (Organismo Participativo de Avaliação da Conformidade Orgânica - OPAC) que utiliza, nos processos de monitoramento e avaliação, a participação direta de produtores, comerciantes, transportadores, armazenadores, consumidores e técnicos. Finalmente, o decreto também previu mecanismos de controle social para venda direta sem certificação. As Organizações de Controle Social (OCS) permitem comercializar produtos orgânicos sem certificação quando os mesmos se destinam à venda direta aos consumidores, ancorando-se, portanto, em premissas de "confiança", ao invés de oportunismo.

A flexibilidade do sistema permitiu aos atores agir de acordo com contextos específicos. Por um lado, possibilitou aos agricultores que comercializam nas feiras-livres utilizar mecanismos de controle social sem certificação (menos custosas), embora, na prática, a maioria recorra à certificação participativa, a qual expressa uma forma mais consolidada de engajamento sociopolítico. Por outro lado, também permitiu aos atores interessados em circuitos de comércio mais convencionais demandar padrões mais "rígidos" (tecnocientíficos) de produção, complementares à normatização nacional. Isso ocorre, por exemplo, em relação às exigências adicionais impostas aos agricultores pela certificação por auditoria. Empresas, supermercados e exportadores definem normas complementares, geralmente associadas a padrões qualitativos estéticos e organolépticos, exigindo a adequação de seus fornecedores. 
Os diferentes espaços de mercado revelam campos sociais envolvendo distintos atores, valores e artefatos. Nos mercados dominados pelas grandes redes varejistas predominam valores industriais e mercantis que sustentam concepções qualitativas que destacam a sanidade e a inocuidade do produto, os quais são incorporados aos parâmetros das empresas de auditoria. Enquanto isso, nas feiras-livres o mercado é conformado, sobretudo, por valores domésticos e cívicos que se ancoram nos laços de proximidade entre produtores e consumidores. Para além do selo da certificação participativa, que em si mesmo já procura incorporar o ideal sociopolítico dos movimentos agroecológicos, os demais dispositivos utilizados nesses espaços também comunicam significados culturais e políticos: embalagens, rótulos, barracas, faixas, cartazes, camisetas... Nas feiras a referência à agroecologia como "movimento sociopolítico" ou como "modo de vida" materializa-se de diversos modos (Radomsky, 2015).

Uma mudança que começa a desafiar a estabilidade desse sistema é a sobreposição de campos sociais e a coexistência dos mecanismos de certificação. Para atender diferentes mercados, muitos agricultores utilizam ambos os dispositivos (certificação por auditoria e participativa), o que, além de encarecer os procedimentos de monitoramento, faz emergir dinâmicas conflitivas entre diferentes ordens valorativas. 0 conflito entre valores mercantis e cívicos estabelece-se, por exemplo, quando o uso da certificação por auditoria exigida por uma rede varejista colide com a pressão social exercida pelas associações para a valorização do selo de certificação participativa, a qual se associa à crítica política aos atores dominantes. Exemplo disso são as embalagens do arroz orgânico/agroecológico comercializado pelos assentamentos de reforma agrária da região metropolitana de Porto Alegre. Reconhecido como uma das experiências de maior sucesso na produção agroecológica em larga escala, diretamente associado ao Movimento dos Trabalhadores Rurais Sem Terra, esse produto circula entre diferentes mercados (feiras, lojas, alimentação escolar, grande varejo e exportação), por- 
tando uma miríade de selos e expressões. A inflação dos selos cria distúrbios políticos dentro do campo, exigindo habilidades sociais para assegurar o engajamento e a cooperação. Com efeito, mais do que um ator econômico, a cooperativa de produtores se torna uma verdadeira "coalizão política", sustentada por compromissos que devem ser reafirmados continuamente, mas sempre passíveis de questionamentos (Fligstein, 2001).

Outro exemplo que embaralha as relações no campo social é a incorporação dos atores e dispositivos da certificação participativa nos mercados convencionais. Em virtude do crescimento exponencial da demanda por produtos orgânicos, as grandes redes varejistas estão flexibilizando a exigência da certificação por auditoria, incluindo gradativamente produtos que passaram pela atestação de sistemas participativos ${ }^{9}$. Enquanto alguns atores sociais destacam que esse processo "desarma" os defensores do discurso tecnocientífico (que creditavam, sem evidências expressivas, maior rigor ao sistema auditado por terceira-parte), outros questionam se o ingresso dos produtos agroecológicos de uma pequena associação de agricultores ecologistas nas grandes redes varejistas pode "desarmar a crítica" que estes atores construíram ao processo de "convencionalização dos orgânicos". Isso porque haveria a possibilidade de fragilizar o vínculo moral até então coerente entre os componentes simbólicos dos dispositivos incorporados aos alimentos agroecológicos e aos espaços arquitetados pelos movimentos sociais para fortalecer estes componentes (Oliveira, 2014; Niederle, 2014a).

Não há como prever o futuro dessas lutas, mas parece cada vez mais claro que a circulação dos atores e dos dispositivos entre distintos mercados reclama uma abordagem mais complexa

9 Nesse mesmo sentido, também chamou atenção durante a pesquisa algumas iniciativas de criação de pontos de feiras-livres nos estacionamentos de grandes shoppings centers em capitais como Porto Alegre (RS) e Vitória (ES), o que aproxima dois mundos sociais recorrentemente tratados de maneira antagônica. 
acerca das configurações dos campos sociais. 0 modelo dual entre "dominantes" e "dominados" pode perder potencial analítico em face da conformação de redes mais flexíveis e dinâmicas (Beckert, 2010). Tanto a noção de "fóruns híbridos", proposta pelos proponentes da teoria do ator-rede (Callon, 1986), quanto a ideia de múltiplas e sobrepostas "ordens sociais", encontrada na teoria das práticas (Schatzki, 2002), podem reclamar espaço na análise do modo, cada vez mais complexo, como os dispositivos adentram a teia de relações sociais.

\section{D ispositivos, práticas e subjetividades}

Um dos aspectos mais importante na análise dos dispositivos é a concepção de que eles operam efeitos práticos, isto é, dinamizam a ação e criam realidades mentais e sociotécnicas. Sob esse ponto de vista se compreende como as práticas sociais constituem os dispositivos e são recursivamente moldadas pelos mesmos (Schatzki, 2002). Neste artigo, até este momento, foram enfatizados os processos de constituição das normas da agricultura orgânica no Brasil. Esta última seção examinará como elas operam como dispositivos de governo de práticas e subjetividades.

O processo de convencionalização da agricultura orgânica é marcado pelo modo como a proliferação das normas e padrões globais permite o ingresso neste mercado de agricultores empresariais, oligopólios agroindustriais e redes varejistas transnacionais, as quais passam a atuar como atores dominantes, com crescente capacidade de controlar o processo de produção dos dispositivos (Niederle; Almeida, 2013). Ao definir a agricultura orgânica como um "sistema técnico", esses atores estabelecem os parâmetros científicos dentro dos quais a crítica social pode ser construída. Assim, a virada ontológica que, segundo os movimentos sociais, a agroecologia representa frente às atuais visões urbano-industriais da agricultura e tecno-racionalistas do conhecimento, é acusada de falta de "realismo" e "objetividade". Geralmente isso vem associado a questionamentos retóri- 
cos, impossíveis de serem respondidos em vista dos parâmetros que os próprios demandantes definem como sendo os únicos legítimos. Esse é o caso, muito em voga atualmente, do questionamento sobre a capacidade da produção agroecológica alimentar o mundo inteiro, a qual ressuscita o pesadelo malthusiano (Niederle; Marques, 2016).

Aqueles que outrora não vislumbravam nos sistemas ecológicos de produção uma alternativa plausível para alimentar o mundo, agora, sob a pressão das crises de saúde pública e da emergência sustentabilidade como novos valores societários, fazem questão de adequar as normas da agricultura orgânica aos arranjos técnico e institucional mais adequados às suas condições de produção e distribuição, de modo que 'tudo mude para continuar exatamente igual'. Para tanto, buscam legitimar-se por meio da crença socialmente construída de que seus instrumentos, normas, métodos, padrões e índices expressam a própria "natureza das coisas". Assim, contornam a ameaça da crítica, de modo que os movimentos ecologistas não conseguem confrontar o novo modelo de dominação gestionária. Os dispositivos são reajustados, mas os atores dominantes mantêm o controle do processo de produção da realidade (Boltanski, 2013).

Afastando a crítica, os porta-vozes da agricultura orgânica conseguem não apenas controlar a produção das práticas agrícolas, mas das identidades sociais. Uma vez definido que a única certificação oficial existente no Brasil é aquela para produtos "orgânicos", os movimentos da agroecologia, da permacultura ou da agricultura biodinâmica e natural foram obrigados a incorporar a nova gramática, com suas regras e convenções. É verdade que esse processo ainda está em curso e inúmeras contradições e resistências permanecem, mas, nos próprios movimentos ecologistas e camponeses mais críticos ao processo desconvencionalização, já é recorrente o uso articulado dos diferentes termos e selos. Cada vez mais, 'agroecológico' e 'orgânico' se confundem, e confundem os discursos, as representações e as identidades 
sociopolíticas, tanto dos produtores quanto dos consumidores.

Os dispositivos criam ainda novas condições para a organização social. 0 elogio à técnica, à produtividade e à eficiência desafiam cotidianamente os agricultores ecologistas e suas organizações. Seus próprios dispositivos são questionados. Muitos agricultores 'fogem' das 'cansativas' reuniões dos grupos de certificação participativa. Eles querem apenas a autorização para utilizar o selo que, neste caso, não tem os altos custos da auditoria externa. Outros tantos preferem trabalhar e comercializar seus produtos individualmente, sem ter que arcar com os custos da participação. Se, por um lado, eles são criticados pelos 'agricultores mais participativos', por outro, amparam-se na legitimidade do discurso dominante: quando aferem lucros mais expressivos, ninguém tem condições de exigir sua expulsão do grupo. Pelo contrário, conseguem com isso aumentar a pressão para que todo o grupo se adéque aos valores do novo espírito do capitalismo.

Na outra ponta da cadeia, no que tange aos consumidores de produtos orgânicos, Guivant (2003) mostrou como a convencionalização associa-se ao crescimento de um estilo de vida que a autora denominou ego-trip, pois as práticas de consumo já não respondem prioritariamente à preocupação ambiental ou às formas de trabalho na agricultura, marcas identitárias de um consumidor ecologista politizado, mas à moral hedônica do cultivo do corpo. A partir disso, pode-se notar que as novas modalidades de governo não se exercem contra a natureza humana- isto é, não se trata de um disciplinamento de corpos rebeldes ou indiferentes -, mas com ela, a favor dela, pois os valores do prazer, do cuidado de si e do corpo saudável fazem parte da gama de desejos das pessoas. Além disso, também é central constatar que as novas formas de dominação acentuam o individualismo, tornando-se simultaneamente um elogio à liberdade. É a partir do discurso da garantia da liberdade dos indivíduos que o corpo se torna foco das técnicas de poder e prazer. Como destaca Foucault, a biopolítica não nega o regime disciplinar; ela o integra, 
valendo-se dos seus sucessos. Por essa razão, o nascimento da biopolítica também se vincula ao surgimento do liberalismo, com a apoteose do individualismo.

As mudanças em curso no setor de orgânicos demonstram a capacidade de governo dos dispositivos. Nos últimos anos são cada vez mais intensos a cobrança e o julgamento sobre os agricultores. Os feirantes, por exemplo, que costumeiramente diziam: "não é orgânico, porém é sem veneno", se veem envolvidos em disputas por legitimidade, haja vista as regras mais transparentes e rígidas de denominação e verificação. Esse também é o caso dos agricultores que abandonam os grupos de certificação participativa, mas mantêm-se nas feiras ecológicas (geralmente construídas pelo esforço coletivo do grupo), onde as formas de fiscalização se tornam cada vez mais frequentes.

É relevante perceber que a construção das normas de orgânicos obedeceu aos processos e condições antes descritos, com a participação de comissões, movimentos sociais, setores privados, ministérios de Estado, etc. Todavia, as agriculturas alternativas e de base ecológica são, evidentemente, anteriores às normas. É inegável que após a publicação das leis, instruções normativas e decretos, os grupos de agricultores ecológicos precisaram se adequar à padronização nacional. As entidades certificadoras participativas começaram a refazer os cadastros de produtores, racionalizar os processos contábeis e técnicos, criar mecanismos de transparência para fiscalização dos órgãos estatais e ampliar o quadro de "profissionais técnicos" para seguir o trabalho.

As modalidades de governo nunca ocorrem sem que os atores se tornem também parte do processo, com diferentes possibilidades de negociação e apropriação. Se, por um lado, os atores empresariais e técnicos lograram implementar normas de certificação adequadas aos seus interesses, os movimentos ecologistas encontraram espaço de manobra para reagir. No sul do Brasil, a experiência da Rede Ecovida realça a indigenização 
desse processo. Foi a partir do esforço de reconstituir a compreensão sobre o que são e como devem ser as certificações que a Rede Ecovida construiu o seu próprio selo. Se a efervescência da agricultura ecológica é tamanha que pode ser alçada a um modo de vida - com profundas convicções ontológicas - a própria natureza da relação com o regime de certificação acentua o caráter sociopolítico da participação, da transição agroecológica e da dimensão total e integradora da produção que fundamenta o sistema de garantia da qualidade orgânica.

Constituída em 1998 por meio de uma articulação entre diversas organizações da agricultura ecológica, a Rede Ecovida engaja-se nos processos de transição agroecológica a partir da troca de experiências em espaços coletivos. Os grupos e núcleos são articulados pela proximidade territorial, geralmente abarcando uma comunidade no interior de um mesmo município, mas sem se limitar à rigidez das fronteiras geográficas oficiais. Esse tipo de enraizamento territorial permite uma organização de base que é fundamental para a troca de informações, conhecimentos e acesso aos canais de comercialização. A conexão entre os grupos envolve ainda uma entidade de coordenação - cooperativa, associação ou ONG - responsável pela articulação entre agricultores, técnicos e consumidores em seu território.

Em 2009, a organização de caráter informal constituiu-se juridicamente enquanto Associação Ecovida de Certificação Participativa, passando a atuar na avaliação da conformidade orgânica enquanto Organismo Participativo de Avaliação da Conformidade (OPAC). Em face às pressões que as redes varejistas e empresas processadoras de alimentos impunham para o uso da certificação com auditoria externa, o principal desafio da Ecovida passou a ser a articulação de novos mercados para seus agricultores, prezando pela imagem de uma agroecologia política, crítica, portadora de significados que extrapolam a ideia de 'técnica produtiva' incorporada pela normatização dos orgânicos (Badomsky; Niederle; Schneider, 2015; Petersen; Mussoi; Dal Soglio, 2013). 
Atualmente, a rede é constituída por 28 núcleos que abrangem 300 grupos em cerca de 170 municípios, 35 organizações, 8 cooperativas de consumo e 3,5 mil agricultores (Niederle, 2014b). 0 principal espaço de mercado construído são as feiras-livres, não tanto em virtude do volume comercializado, mas do potencial que a proximidade entre produtores e consumidores cria para o manejo dos dispositivos ${ }^{10}$. É ali que os agricultores exploram discursivamente as diferenças entre seus produtos ecológicos, oriundos de um sistema agrícola diversificado, cultivado por suas famílias, e os produtos orgânicos agroindustriais que, cada vez mais, preenchem as prateleiras dos supermercados. É ali que eles encontram uma espécie de nicho que lhes garante não apenas a reprodução social, mas as condições de projetar suas críticas ao sistema dominante, manejando um conjunto de dispositivos (principalmente, mas não exclusivamente um "selo") com vistas a consolidar práticas, identidades e subjetividades.

Atualmente, um dos principais desafios desta rede é sustentar seus valores doméstico-cívicos em face da pressão que o novo modelo de dominação produz cotidianamente sobre os agricultores e consumidores. Já mencionamos acima a incorporação da certificação participativa pelos oligopólios varejistas. No entanto, existem outros dilemas igualmente relevantes, incluindo as críticas emergentes ao próprio processo de certificação, ainda que participativo. Ao mesmo tempo em que criam alternativas de mercado para os agricultores ecologistas, esses dispositivos "disciplinam" os comportamentos, são incorporados nas rotinas da vida social, moldam não apenas as relações, mas os corpos e a natureza. E, por conta disso, são cada vez mais contestados. Cabe notar que, associada ao selo está uma miríade de formu-

10 Nesse mesmo sentido, outro espaço de mercado fundamental, criado a partir do encontro entre os movimentos sociais e os atores estatais, são as compras governamentais, sobretudo aquelas voltadas para alimentação escolar. Além de envolver um volume expressivo de produtos, é um circuito em que, como vários estudos têm revelado, o ingresso de alimentos agroecológico tem produzido efeitos importantes de ressignificação das práticas de produção e consumo (Teo; Triches, 2016). 
lários, cadastros, planos de conversão, regras de produção e padrões. As pressões que esses dispositivos exercem cotidianamente sobre a vida têm levado alguns agricultores a abdicar de todo o sistema. Como já ocorre em vários outros países, eles buscam circuitos curtos de comercialização que não demandam qualquer tipo de certificação. Se, por um lado, isso lhes coloca obstáculos para o uso do selo "orgânico" e, portanto, para comercializar em mercados mais extensos, por outro, lhes retorna o controle sobre a produção de suas vidas (práticas, identidades e subjetividades).

\section{Considerações Finais}

Os modos complexos como os dispositivos se projetam na organização da vida social têm ampliado o interesse de diferentes disciplinas. Inúmeras abordagens proliferaram com vistas a analisar as múltiplas faces desse fenômeno. Até o momento, nenhuma parece ter condições de abarcá-lo integralmente. E talvez seja excessivamente pretensioso imaginar que isso seja possível. No entanto, o crescente diálogo entre elas tem produzido interessantes resultados. Em particular, as tentativas mais recentes de reaproximação entre vertentes da teoria crítica e pragmática (Boltanski, 2009) estimulam analisar como os dispositivos são socialmente produzidos, manejados pelos atores no transcurso das lutas sociais, e, ao mesmo tempo, em face de sua capacidade performativa, afetam recursivamente a ação destes mesmos atores.

Neste artigo demonstramos como o processo de produção das normas e padrões para os alimentos orgânicos esteve diretamente associado às lutas pelo controle deste mercado emergente. Esse processo envolveu a construção de dispositivos, sobretudo de um sistema de certificação, que, uma vez estabilizado, passou a orientar as práticas sociais (incluindo as práticas discursivas) e, a partir daí, a produção de sentidos, subjetividades e identidades. 0 artigo também demonstrou que, ao mesmo 
tempo em que a convencionalização dos orgânicos ampliou a capacidade de disposição dos atores líderes dos mercados alimentares, que passaram a coordenar o processo de governo, os movimentos ecologistas conseguiram construir habilidades sociais - incluindo o diálogo com atores estatais - não apenas para reagir às estratégias dos atores dominantes, mas para criar dispositivos específicos, dentre os quais o mais importante é o selo da certificação participativa.

Os resultados também apontaram para as reconfigurações atualmente em curso no mercado. Por um lado, o leque de atores tem se tornado mais amplo e heterogêneo, respondendo a própria dinâmica de diferenciação do mercado. A ideia outrora em voga de que cada mercado operaria com um conjunto específico de dispositivos e atores se torna cada vez mais problemática. 0 intercruzamento de diferentes campos sociais reclama abordagens que consigam apreender movimentos mais dinâmicos e instáveis. Por outro lado, chama atenção que o principal desafio dos grupos desafiantes (movimentos ecologistas) não parece mais ser a produção dos seus "próprios" dispositivos e espaços de mercado, nem sequer a colonização dos mesmos pelos atores incumbentes (empresas, supermercados, certificadoras), mas o fato de que eles também foram impelidos a responder à mesma lógica biopolítica, com suas formas legitimadas de conhecimento e poder. Os mecanismos de dominação gestionária se impõem a todos os atores, sem que eles consigam perceber que não há nada de "natural" nas normas, padrões, indicadores e índices que governam suas vidas. É verdade que determinados atores têm maior capacidade de controlar o processo de produção dos dispositivos, e têm uma relação mais dessacralizada com os mesmos, mas ainda assim agem como se suas escolhas repercutissem a própria realidade do mundo, ou seja, a natureza das coisas. 


\section{Ref erências}

ALLAIRE, G; BOYER, R. (Org.). La grande transformation de l'agriculture. Paris: INRA/Economica, 1995.

ALPHANDÉRY, P.; DJAMA, M.; FORTIER, A.; FOUILLEUX, E. (Orgs.). Normaliser au nom du développement durable: dispositifs, savoirs, politiques, Paris: Quae, 2012.

APPLETON, A. E. Environmental labeling schemes revisited: WTO law and developing country implications. In: SAMPSON, G. P. (Ed.). Trade, environment, and the millennium.United Nations University Press, 2001. p. 235-66.

BATIFOULIER, P.; LARQUIER, G. De la convention et de ses usages. In: BATIFOULIER, P. (dir.) Théorie des conventions. Paris: Economica, 2001. p.09-31.

BECKERT, J. How Do Fields Change? The Interrelations of Institutions, Networks, and cognition in the Dynamics of Markets. Organization Studies, v. 31, n. 5, p. 605-27, 2010.

BIGGART, N. W.; BEAMISH, T. D. The Economic Sociology of Conventions: habit, custom, practice, and routine in market order. Annual Review of Sociology, v. 29, p. 443-64, 2003.

BINGEN, J.; BUSH, L. Agricultural Standards: the shape of the global food and fiber system. Dordrecht: Springer, 2007.

BLANDIN, B. La construction du social par les objecs. Paris: PUF, 2002.

BLASER, M. Storytelling globalization: from the Chaco and beyond. Durham: Duke University Press, 2010.

BLOCK, F.; EVANS, P.The State and the Economy. In: SMELSER, N.; SWEDBERG, R. (Eds.). Handbook of EconomicSociology. Princeton, 2005.

BOLTANSKI, L. Sociologia da crítica, instituições e o novo modelo de dominação gestionária. Sociologia \& Antropologia, v. 3, n. 6, p. 441-63, 2013.

BOLTANSKI, L. De la critique. Paris: Gallimard, 2009.

BOLTANSKI, L.; THEVENOT, L. De la justification. Paris: Gallimard, 1991.

BOSTRÖM, M.; KLINTMAN, M. Eco-standards, product labelling and green consumerism. Hampshire: PalgraveMacmillan, 2008.

BOURDIEU, P. A distinção: crítica social do julgamento. São Paulo: Edusp; Porto Alegre, RS: Zouk, 2007.

BUSCH, L. Standards: recipes for reality. Cambridge: MIT, 2013. 
BUSCH, L. The private governance of food: equitable exchange or bizarre bazaar? Agriculture and Human Values, v. 28, p. 345-52, 2011.

CALLON, M. Eléments pour une sociologie de la traduction: la domestication des coquilles Saint-Jacques et des marins-pêcheurs dans la baie de SaintBrieuc. L’annésociologique, n.36, p.169-208, 1986.

CALLON, M. (Org.).The laws of the markets. Oxford: Blackwell, 1998. pp. 1-57.

CALLON, M. Dos estudos de laboratório aos estudos de coletivos heterogêneos, passando pelos gerenciamentos econômicos. Sociologias, v.10, n.19, p.302-21, 2008.

CALLON, M.; MÉADEL, M.; RABÉHARISOA, V. The economy of qualities. Economy and Society, v. 31, n. 2, p. 194-217, 2002.

DOUGLAS, M. Como as instituições pensam. São Paulo: EDUSP, 1998.

EYMARD-DUVERNAY, F. Conventions de qualité et formes de coordination. Revueéconomique, v.40, n.2, p.329-59, 1989.

FEIGENBAUM, A.V. Controle da qualidade total. São Paulo: Makron Books, 1994.

FLIGSTEIN, N. Fields, Power, and Social Skill: A Critical Analysis of The New Institutionalisms, 1997. (mimeo)

FLIGSTEIN, N. Mercado como política: uma abordagem político-cultural das instituições de mercado. Contemporaneidade e Educação, v. 6, n. 9, p. 26-55, 2001.

FLIGSTEIN, N.; McADAM, D. Toward a General Theory of Strategic Action Fields. Sociological Theory, v. 29, n. 1, 2011.

FONSECA, M. F. de A. C. A institucionalização dos mercados de orgânicos no mundo e no Brasil: uma interpretação. 2005. Tese (Doutorado em Desenvolvimento, Agricultura e Sociedade). Rio de Janeiro: UFRRJ, 2005.

FOUILLEUX E., 2012. Vers une agriculture durable? Normes volontaires et privatisation de la régulation. In: JACQUET, P.; PACHAURI, R.; TUBIANA, L. (Eds.). Développement, alimentation, environnement: changer l'agriculture? $\mathrm{Pa}$ ris: Armand Colin, 2012. pp. 301-10.

FOUCAULT, M. Segurança, território, população: Curso no Collège de France (1977-1978). São Paulo, Martins Fontes, 2008a.

FOUCAULT, M. O nascimento da biopolítica. Curso no Collège de France (1978-1979). São Paulo, Martins Fontes, 2008b.

FOUCAULT, M. Em defesa da sociedade. Curso no Collège de France (19751976). São Paulo, Martins Fontes, 1999. 
GOODMAN, D.; GOODMAN, M. Localism, livelihoods and the 'post-organic': changing perspectives on alternative food networks in the United States. In: MAYE, D.; HOLLOWAY, L.; KNEAFSEY, M. (Ed.). Alternative food geographies: representation and practice. Amsterdan: Elsevier, 2007. p. 23-38.

GUÉNEAU S. Certification as a new private global forest governance system: the regulatory potential of the Forest Stewardship Council. In: FÖSTER, T.; PETERS, A. (Orgs.). Non-State Actors in Standard Setting. Cambridge, Cambridge University, 2009.

GUIVANT, J. Os supermercados na oferta de alimentos orgânicos: apelando ao estilo de vida ego-trip. Ambiente e Sociedade, v. 6, n. 2, p. 63-81, jul./dez. 2003.

GUTHMAN J. The trouble with 'organic lite' in California: a rejoinder to the 'conventionalisation' debate. Sociologia Ruralis, v. 44, p. 301-16, 2004.

HATANAKA, M.; BAIN, C.; BUSCH, L. Third-party certification in the global agrifood system. Food Policy, 30, p. 354-69, 2005.

HODGSON, G. What are institutions? Journal of Economic Issues, v. 40, n. 1, 2006.

HONNETH, A. Reification: A Recognition-Theoretical View. Conferênciana University of California-Berkeley, March 14-6, 2005.

HOWARD, P. H.; ALLEN, P. Beyond organic: consumer interest in new labeling schemes in the Central Coast of California. International Journal of Consumer Studies, v. 30, n. 5, p. 439-51, 2006.

ILBERY, B.; MORRIS, C.; BULLER, H.; MAYE, D.; KNEAFSEY, M. Product, process and place: an examination of food marketing and labelling schemes in Europe and North America. European Urban and Regional Studies, v. 12, n. 2, p. 11632, 2005.

JOHNSON, W.B.; LYS, T.The market for audit services: evidence from voluntary auditor changes, v. 12, n. 1-3, p. 281-308, 1990.

LASCOUMES, P.; LE GALÈS, P. Gouverner par les instruments. Paris: Sciences Po, 2004.

LATOUR, B. Reensamblar lo social: una introducción a la teoría del actor-red. Buenos Aires: Manantial, 2008.

LYON, S. Migratory imaginations: the commodification and contradictions of shade grown coffee. Social Anthropology, v. 14, n. 3, p. 377-90, 2006.

MANSFIELD, B. Organic views of nature: the debate over organic certification for aquatic animals, SociologiaRuralis, v. 44, n. 2, p. 216-32, 2004. 
MILLER, P. Governing by numbers: why calculative practices matter. Social Research, v. 68 n. 2, p. 379-96, 2001.

NICOLAS, F; VALCESCHINI, E. Agroalimentaire: une économie da la qualité. Paris: INRA-Economica, 1995.

NIEDERLE, P.A. Políticas de valor nos mercados alimentares: movimentos sociais econômicos e a reconstrução das trajetórias sociais dos alimentos agroecológicos. Século XXI - Revista de Ciências Sociais, v. 4, p. 162-89, 2014a.

NIEDERLE, P.A. Os agricultores ecologistas nos mercados para alimentos orgânicos: contramovimentos e novos circuitos de comércio. Sustentabilidade em Debate, v. 5, n. 3, p. 79-96, 2014 b.

NIEDERLE, P.A.; ALMEIDA, L. A nova arquitetura dos mercados para produtos orgânicos: o debate da convencionalização. In: NIEDERLE, P.A.; ALMEIDA, L; VEZZANI, F.M. (Org.). Agroecologia: práticas, mercados e políticas para uma nova agricultura. 1ed. Curitiba: Kairós, 2013, v. 1, p. 23-67.

NIEDERLE, P.A.; MARQUES, F.C. Produção ecológica de alimentos e mudanças institucionais: implicações para a construção de novos mercados. In: MARQUES, F.C.; CONTERATO, M.A.; SCHNEDIER, S. (Org.). Construção de mercados e agricultura familiar: desafios para o desenvolvimento rural. 1 ed. Porto Alegre, 2016. pp. 275-310.

OLIVEIRA, D. Produção de conhecimentos e inovações na transição agroecológica: o caso da agricultura ecológica de Ipê e Antônio Prado - RS. Tese (Doutorado em Desenvolvimento Rural). Porto Alegre: UFRGS, 2014.

OSTROM, E. Beyond Markets and States. Nobel Prize Lecture, December 8, 2009.

PETERSEN, P., MUSSOI, E.; DAL SOGLIO, F. Institutionalization of the agroecological approach in Brazil: advances and challenges. Agroecology and Sustainable Food Systems, v. 37, n. 1, p. 103-14, 2013.

PONTE, S.; GIBBON, P. Quality standards, conventions and the governance of global value chains. Economy and Society, v.34, n.1, p.1-31, 2005.

PONTE S., VESTERGAARD, J., GIBBON, P. (Orgs.). Governing Through Standards: Origins, Drivers and Limits, London: Palgrave, 2011.

RADOMSKY, G.F.W. O poder do selo: imaginários ecológicos, formas de certificação e regimes de propriedade intelectual no sistema agroalimentar. Porto Alegre: Ed. da UFRGS, 2015.

RADOMSKY, G.F.W.; NIEDERLE, P.; SCHNEIDER, S. Participatory systems of certification and alternative marketing networks: the case osEcovida Agroecology 
Network in South Brazil. In: HEBINCK, P.; PLOEG, J.D.; SCHNEIDER, S. (Org.). Rural Development and the Construction of New Markets. The Hague: Routledge, 2015. pp. 79-98.

RAMOS, E; GARRIDO, D. Towards a " $2^{\text {nd }}$ generation" of quality labels: a proposal for the evaluation of territorial quality marks. Cuadernos de Desarrollo Rural, v.11, n.74, Bogotá, jul./dez. 2014.

RENTING, H.; MARSDEN, T.; BANKS, J. Understanding alternative food networks: exploring the role of short food supply chains in rural development. Environment and Planning, v. 35, p. 393-411, 2003.

SCHATZKI, T.R. The site of the social: a philosophical account of the constitution of social life and change. Philadelphia: Pennsylvania State University Press, 2002.

SCHMIDT, V. Discursive Institutionalism: The Explanatory Power of Ideas and Discourse. Annual Review of Political Science, v. 11, p. 303-26, 2008.

SHORE, C.; WRIGHT, S. Governing by numbers: audit culture, rankings and the new world order. Social Anthropology, v. 23, n. 1, p. 22-8, 2015.

STRATHERN, M. Audit cultures: anthropological studies in accountability, ethics and the academy. London: Routledge, 2000

TEO, C. R.; TRICHES, R. M. (Org.). Alimentação Escolar: construindo interfaces entre saúde, educação e desenvolvimento. Chapecó: Argos, 2016.

THÉVENOT, L. Un gouvernement par les normes: pratiques et politiques des formats d'information. In: CONEIN, B.; THEVENOT, L. Cognition et information en société. Paris: EHESS (Raisons Pratiques 8), 1997, p. 205-41.

THÉVENOT, L. Certifying the world: power infraestructures and practices in economies of conventional forms. IN: ASPERS, P.; DODD, N. Re-Imagining Economic Sociology. Oxford: Oxford University Press, 2015, p. 195-223.

THEVENOT, L. Les investissements de forme. In : (ed.) Conventions économiques. Paris: Presses Universitaires de France, 1986. p.21-71.

WILKINSON, J.; NIEDERLE, P.; MASCARENHAS, G. O Sabor da Origem: produtos territorializados na nova dinâmicas dos mercados alimentares. Porto Alegre: Escritos, 2016.

WILLIAMSON, O. As instituições econômicas do capitalismo. São Paulo: Pezco, 2012.

Recebido em 24/02/2017

Aprovado em 31/05/2017 
